\title{
Arterialised earlobe blood gas analysis: an underused technique
}

\author{
A D Pitkin, C M Roberts, J A Wedzicha
}

\begin{abstract}
Background - Techniques for sampling arterialised capillary blood from the finger pulp and the earlobe were first described over two decades ago but, although close agreement between arterial values and earlobe samples has been demonstrated in normal subjects, this technique is not in common usage.

Methods - Forty patients with chronic lung disease and a wide range of arterial blood gas values were studied. Simultaneous earlobe and arterial samples were drawn with the patient at rest and analysed in the same blood gas analyser. The respiratory function laboratory staff in 50 UK hospitals with a respiratory department were telephoned and asked whether the technique was used in their hospital and the reasons, if known, for not adopting it.
\end{abstract}

Results - Earlobe and arterial blood gas tensions agreed closely over a wide range of values of arterial $\mathbf{p H}, \mathrm{Pco}_{2}$ (mean difference $0.21,95 \%$ confidence intervals -0.24 to $+0.67 \mathrm{kPa}$ ) and $\mathrm{Po}_{2}$ (mean difference $-0 \cdot 17,95 \%$ confidence intervals -1.09 to $+0.75 \mathrm{kPa}$ ), especially at arterial $\mathrm{Po}_{2}$ values lower than $8 \mathrm{kPa}$. Of $50 \mathrm{UK}$ centres surveyed $18 \%$ used the arterialised earlobe technique and $4 \%$ had plans to introduce it. Reasons for not using it were lack of knowledge in $64 \%$, no blood gas analyser in $6 \%$, the technique was considered inaccurate in $4 \%$, and insufficient staff in $4 \%$.

Conclusions - Although earlobe blood gas analysis is sufficiently accurate to be reliably substituted for arterial sampling in routine clinical practice, most centres in the UK do not use the technique. The main reasons for this appear to be lack of knowledge of its existence and uncertainty over its accuracy.

(Thorax 1994;49:364-366)

Department of Thoracic Medicine, London Chest Hospital, Bonner Road, London E2 9]X A D Pitkin C M Roberts J A Wedzicha

Reprint requests to: Dr J A Wedzicha.

Received 21 September 1993 Returned to authors 24 November 1993 Revised version received 30 December 1993 Accepted for publication 4 January 1994

Measurement of arterial blood gas tensions is a routine part of the assessment of patients with acute and chronic respiratory disorders producing abnormalities of gas exchange. Blood sampling by direct arterial puncture is the accepted technique established in clinical practice. This method, however, requires qualified medical staff to perform it and may result in significant discomfort and morbidity for the patient. ${ }^{1}$ Alternative methods such as cutaneous pulse oximetry have also been used to estimate arterial oxygen tension but corre- late poorly with arterial $\mathrm{PO}_{2}$ values on the steep phase of the oxyhaemoglobin dissociation curve. $^{2}$ Transcutaneous carbon dioxide measurement is an even less accurate technique and it is relatively cumbersome and time consuming to obtain single estimations. ${ }^{3}$

Techniques for sampling of arterialised capillary blood from the finger pulp and the earlobe were first described over two decades ago. ${ }^{45}$ Although close agreement with arterial values and earlobe samples has been shown, ${ }^{6}$ the technique is not in common usage. These studies used small numbers of normal volunteers, undergoing physiological exercise testing, who had a relatively limited range of arterial blood gas values. ${ }^{7}$ Patients with chronic lung disease have a much wider range of arterial blood gas tensions, and close agreement between arterial and earlobe blood gas values in this group has not yet been demonstrated.

We therefore undertook a study to assess the accuracy of this technique in measuring arterial blood gas tensions in patients with chronic respiratory disorders and with a wide range of values of arterial $\mathrm{PO}_{2}$ and $\mathrm{PCO}_{2}$. We also conducted a survey of other hospitals to find out how commonly the technique is used elsewhere, and the reasons, if any, for not adopting this method.

\section{Methods}

Forty patients with chronic respiratory disease were studied. Their diagnoses were chronic obstructive pulmonary disease and bronchiectasis (29 patients), restrictive disorders including kyphoscoliosis, ankylosing spondylitis, thoracoplasty (eight patients), sarcoidosis (two patients), and one patient being investigated for breathlessness with no identifiable cause. Median forced expiratory volume in one second $\left(\mathrm{FEV}_{1}\right)$ was 0.77 (range $\left.0.38-2.7\right) 1$ and median forced vital capacity (FVC) was 1.7 (range 0.89-4.3) 1 .

Each patient had simultaneous capillary and arterial samples taken at rest which were measured by the same analyser (Radiometer val of no more than five minutes between samples. Earlobe samples were taken by one of four technicians experienced in the technique. The method of capillary sampling was as previously described ${ }^{7}$ and involves spreading an earlobe (usually the patient's left, with a right handed operator) with nicotinate paste (Algipan or similar) for at least 10 minutes to induce capillary vasodilatation. A stab incision is made in the inferolateral aspect of the pinna from which blood usually flows freely (this is 
Comparative data for $\mathrm{pH}, \mathrm{PO}_{2}$ and $\mathrm{PCO}_{2}$ values of simultaneous arterial and capillary blood samples in 40 patients

\begin{tabular}{lllll}
\hline & Range & Maximum difference & Mean difference & $95 \%$ limits of agreement \\
\hline $\mathrm{pH}$ & $7.32-7.50$ & 0.034 & +0.007 & -0.008 to +0.022 \\
$\mathrm{PCO}_{2}(\mathrm{kPa})$ & $3.87-10.03$ & 0.78 & +0.21 & -0.24 to +0.67 \\
$\mathrm{Po}_{2}(\mathrm{kPa})$ & $4.42-12.97$ & -1.6 & -0.17 & -1.09 to +0.75 \\
\hline
\end{tabular}

Figure 1 (A) Earlobe capillary $\mathrm{Po}_{\mathrm{v}} \mathrm{v}$ arterial $\mathrm{PO}_{2} ;(\mathrm{B})$ difference between earlobe and arterial $\mathrm{PO}_{2} v$ mean $\mathrm{Po}_{2}$.

important) but may require a small amount of manual massage. The arterialised blood collects in a drop on the inferior aspect of the earlobe. It is drawn into a thin glass capillary tube by surface tension under the control of a gloved finger over the open end of the tube and then aspirated into the analyser.

Arterial samples were collected directly into a preheparinised $3 \mathrm{ml}$ plastic syringe by direct puncture of the radial artery.

Respiratory function laboratories in 50 hospitals around the UK were contacted by telephone. They consisted primarily of teaching hospitals and centres with an interest in respiratory medicine. The senior laboratory technician was asked how routine blood gas measurements were performed in that hospital. If the earlobe blood gas technique was known they were asked the reasons, if any, for not using it.

Simple descriptive statistics for the $\mathrm{pH}, \mathrm{Po}_{2}$, and $\mathrm{PCO}_{2}$ values obtained with each technique were calculated, consisting of mean differences and $95 \%$ confidence intervals for arterial and earlobe blood gas tensions. The data are shown graphically using simple scatter plots of ear-
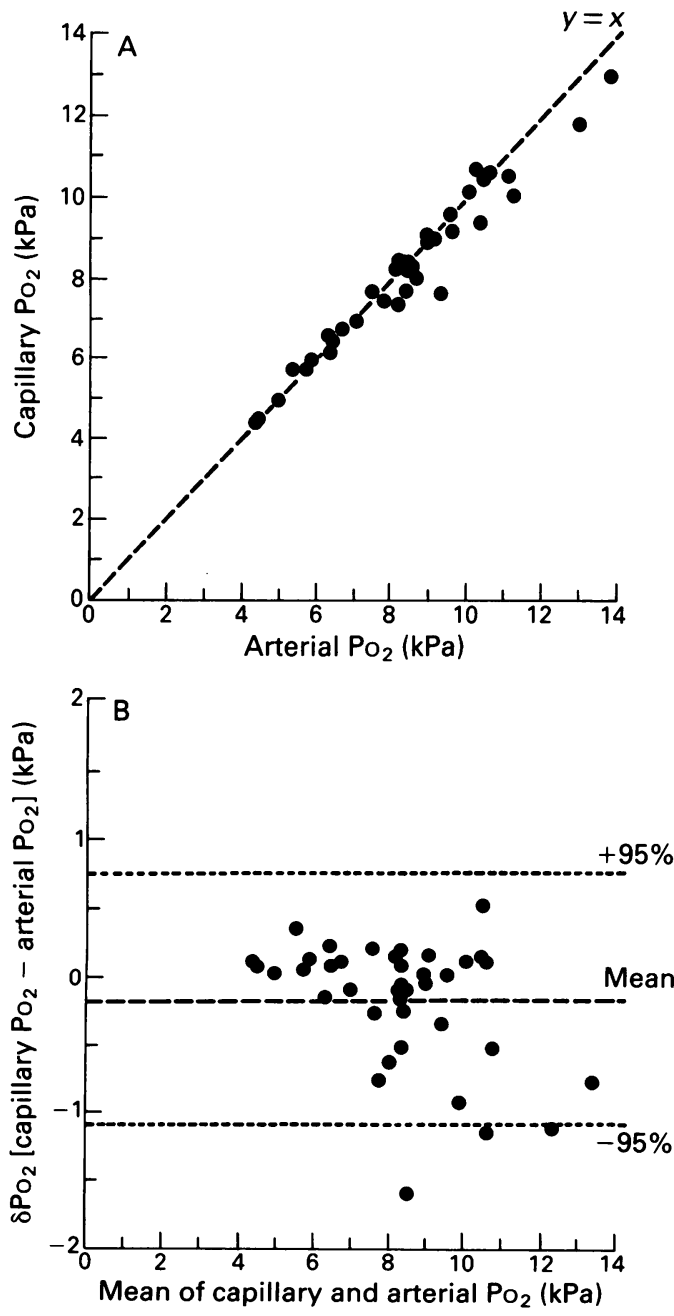

lobe $\mathrm{Po}_{2} v$ arterial $\mathrm{Po}_{2}$ and earlobe $\mathrm{PCO}_{2} v$ arterial $\mathrm{PCO}_{2}$. They were also plotted as the difference between arterial and earlobe values $v$ the mean value as recommended by Bland and Altman. ${ }^{8}$

\section{Results}

The range, mean, standard deviation, and 95\% limits of agreement for $\mathrm{pH}$ and blood gas values obtained by simultaneous sampling of earlobe capillary and arterial blood in 40 patients are shown in the table. The concordance between earlobe and arterial blood gas tensions was good throughout a wide range of values of arterial $\mathrm{Po}_{2}$ (fig 1 ) and $\mathrm{PCO}_{2}$ (fig 2). A particularly good correlation between samples was observed at arterial $\mathrm{Po}_{2}$ values lower than $8 \mathrm{kPa}$. Above this level earlobe $\mathrm{Po}_{2}$ values tended to be slightly lower than arterial $\mathrm{Po}_{2}$ values. Nearly all values, however, lie within $0.5 \mathrm{kPa}$ or less and underestimation of true arterial $\mathrm{PO}_{2}$ at higher levels of oxygenation is unlikely to be of clinical significance. The correlation between $\mathrm{PCO}_{2}$ measurements derived from the two methods is even better with the earlobe technique, tending towards slightly higher values. The mean difference between samples was, however, only $0.21 \mathrm{kPa}$.

Fifty hospitals were surveyed by telephone. Of these, nine (18\%) used the arterialised earlobe technique and two $(4 \%)$ had plans to introduce it. In $32(64 \%)$ of the 39 remaining hospitals the main reason for not using earlobe blood gases was that the laboratory staff were unaware of the technique. In three hospitals $(6 \%)$ a blood gas analyser was not available in the laboratory. In two centres $(4 \%)$ the technique was thought to be inaccurate, and in a further two $(4 \%)$ there were insufficient technical staff to carry out the procedure.

\section{Discussion}

The close agreement between arterial and earlobe blood gas values found in our study confirms the findings of earlier work in normal subjects where earlobe blood gas values have been found to be sufficiently accurate for use in exercise testing to calculate cardiac output, venous admixture, and dead space.$^{67}$ Our findings indicate that this accuracy extends throughout the much wider ranges of arterial $\mathrm{Po}_{2}$ and $\mathrm{PCO}_{2}$ found in patients with respiratory disease, and suggest that earlobe blood gas analysis can reliably be extended from a research technique into routine clinical practice.

Earlobe blood gas measurement could have a valuable role in the assessment of patients for long term oxygen therapy in accordance with published guidelines. ${ }^{910}$ Although pulse oximetry is useful for screening, ${ }^{112}$ it is not sufficiently precise to be substituted for direct arterial $\mathrm{Po}_{2}$ measurement. ${ }^{13}$ Earlobe blood gas analysis, however, is particularly accurate at arterial $\mathrm{Po}_{2}$ values less than $8 \mathrm{kPa}$, can determine arterial $\mathrm{PCO}_{2}$, and is painless enough to allow several samples to be taken on a single occasion with the patient breathing oxygen at varying flow rates to ensure adequate correc- 
Figure 2 (A) Earlobe capillary $\mathrm{PCO} v$ arterial $\mathrm{PCO}_{2} ;(B)$ difference between earlobe and arterial $\mathrm{PCO}_{2} v$ mean $\mathrm{PCO}_{2}$.
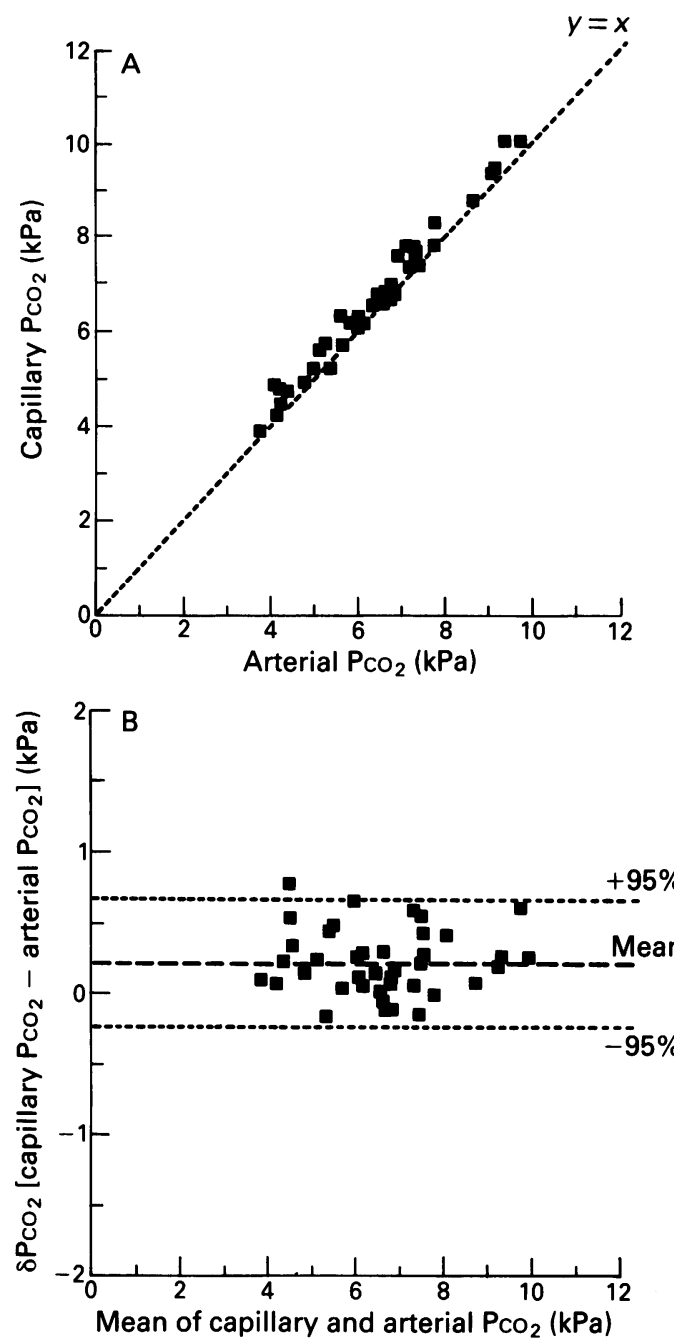

tion of their hypoxaemia. Thus, provision of this technique on an outpatient basis would facilitate appropriate prescription of long term oxygen therapy (LTOT) by general practitioners. Although this may necessitate additional technician time in the lung function laboratory, it would eliminate the need for qualified medical staff to perform arterial puncture. Additional savings might be made by reducing inappropriate prescription of LTOT. At this hospital over 3000 earlobe blood gas measurements are performed each year on inpatients and outpatients. Many of them spontaneously indicate their preference for earlobe sampling.

Collection of arterialised earlobe samples does not occur within a closed system and therefore the technique poses a theoretical risk of infection to the operator from exposure to the patient's blood. The amount involved is small (about 1-2 ml), but appropriate measures to eliminate any possible hazard of infection should be used. In our unit the operator wears gloves and an absorbent disposable towel is placed underneath the earlobe. The tiny incision bleeds for a few seconds only and is then dressed with a small waterproof plaster. In contrast, arterial puncture exposes the operator to the risk of a needlestick injury and, furthermore, inoculation of blood is more likely with the low friction syringes often used for blood gas analysis. Spillage of the contents of the syringe may also occur during injection of the sample into some analysers; this is less likely to occur during aspiration of an earlobe sample from its glass capillary tube.

Our survey included most of the teaching hospitals and specialist centres for respiratory medicine within the UK, and this sample may be biased towards units more likely to employ the technique. The proportion of all UK hospitals using earlobe blood gas analysis is unlikely to be higher than the $18 \%$ found in our survey, which also suggests that the main reason for not using it is lack of knowledge of the technique's existence or its accuracy. Other reasons identified in our survey for not using earlobe blood gas analysis, such as availability of staff and blood gas analysers, are logistical and unique to each centre. Concern that delayed analysis of the sample renders the result inaccurate applies more to conventional plastic syringes than to glass capillary tubes which have been shown to preserve blood gas tensions better than glass or plastic syringes at room temperature. ${ }^{714}$

In summary, based on the results of this study we conclude that earlobe blood gas analysis is a valuable technique in the management of patients with all forms of respiratory disease producing abnormalities of gas exchange, and that only a minority of centres use it. The principal reasons for its underuse are a lack of awareness of its existence and concern over its accuracy, neither of which should preclude its adoption in many more hospitals in the UK.

The authors thank Leonette John, Carol Hodder, Nicky Holbrook, and Colleen Arthur from the Lung Function Laboratory for their assistance with arterialised earlobe blood samples.

1 Flenley DC. Arterial puncture. In: Procedures in Practice. 2nd ed. London: British Medical Journal, 1988:3-5.

2 Clark JS, Votteri B, Ariagno RL, Cheung P, Eichhorn JH, Fallat RJ, et al. Noninvasive assessment of blood gases. Fallat RJ, et al. Noninvasive assessmen Respir Dis 1992;145:220-32.

3 Kost GJ, Chow JL, Kenny M. Unpredictable fluctuations in transcutaneous $\mathrm{PcO}_{2}$ from capillary blood determinations. Clin Chem 1982;28:1514-6

4 Langlands JH, Wallace WF. Small blood samples from earlobe puncture: a substitute for arterial puncture. Lancet 1965;ii:315-7.

5 Christoforides C, Miller JM. Clinical use and limitations of arterialized capillary blood for $\mathrm{Po}_{2}$ determination. $\mathrm{Am}$ Rev Respir Dis 1968;98:653-7.

6 Godfrey S, Wozniak ER, Courtney Evans RJ, Samuels CS Ear lobe blood samples for blood gas analysis at rest and Ear lobe blood samples for blood gas analysis at

7 Spiro SG, Dowdeswell IRG. Arterialized earlobe blood samples for blood gas tensions. $\mathrm{Br} f \mathrm{Dis}$ Chest 1976;70:263-8.

8 Bland JM, Altman DG. Statistical methods for assessing agreement between two methods of clinical measurement. Lancet 1986;i:307-10.

9 Medical Research Council Working Party. Long term domiciliary oxygen therapy in chronic hypoxic cor pulmonale complicating chronic bronchitis and emphysema: report of the MRC working party. Lancet $1981 ; \mathrm{i}: 681-6$.

10 Nocturnal Oxygen Therapy Trial Group. Continuous or nocturnal oxygen therapy in hypoxemic chronic obstrucnocturnal oxygen therapy in hypoxemic chronic obstr

11 Roberts CM, Bulger JR, Melchor R, Hetzel MR, Spiro SG. Value of pulse oximetry in screening for long term oxygen Value of pulse oximetry in screening for long term ox

12 Pierson DJ. Pulse oximetry versus arterial blood gas speciPierson DJ. Pulse oximetry versus arterial blood gas speci-
mens in long-term oxygen therapy. Lung 1990;Suppl: 782-8.

13 Carlin BW, Clausen JL, Ries AL. The use of cutaneous oximetry in the prescription of long-term oxygen therapy. Chest 1988;94:239-41.

14 MacIntyre J, Norman JN, Smith G. Use of capillary blood in measurement of arterial $\mathrm{Po}_{2}$. BMF 1968;3:640-3. 